\title{
Significance of the vascular endothelial growth factor and the macrophage migration inhibitory factor in the progression of hepatocellular carcinoma
}

\author{
DONG WANG $^{1 *}$, LIANG LUO ${ }^{2 *}$, WEI CHEN ${ }^{3}$, LIAN-ZHOU CHEN $^{4}$, \\ WEN-TAO ZENG ${ }^{4}, \mathrm{WEN} \mathrm{LI}^{4}$ and XIAO-HUI HUANG ${ }^{4}$ \\ Departments of ${ }^{1}$ Laboratory Medicine, ${ }^{2}$ Medical Intensive Care Unit, ${ }^{3}$ Hepatobiliary Surgery and \\ ${ }^{4}$ General Surgical Laboratory, The First Affiliated Hospital of Sun Yat-Sen University, Guangzhou 510080, P.R. China
}

Received November 15, 2013; Accepted December 16, 2013

DOI: $10.3892 /$ or.2013.2946

\begin{abstract}
The aim of the present study was to investigate the expression of vascular endothelial growth factor (VEGF) and macrophage migration inhibitory factor (MIF) in HCC progression and their correlation with clinicopathological factors as well as the relationship between their expression levels. The expression of serum VEGF and MIF was evaluated in 150 patients with HCC and in 30 normal volunteers by enzyme-linked immunosorbent assay (ELISA). VEGF and MIF expression levels were evaluated by immunohistochemistry on tissue microarrays containing 150 HCCs with paired adjacent non-cancer liver tissues. VEGF and MIF mRNA levels were determined by quantitative PCR in another 48 HCCs. The correlation of VEGF and MIF with clinicopathological factors was analyzed in HCC. Serum VEGF and MIF concentrations were higher in HCC patients than the levels in the controls. The expression levels of VEGF and MIF in the HCC tissues were both higher than those in the adjacent non-tumor liver tissues. Overexpression of VEGF and MIF was significantly associated with tumor size $(\mathrm{P}=0.027$ and 0.022 , respectively), intrahepatic metastasis $(\mathrm{P}=0.032$ and 0.027 , respectively), vascular invasion $(\mathrm{P}=0.044$ and 0.039 , respectively) and TNM stage $(\mathrm{P}=0.028$ and 0.013 , respectively). Furthermore, VEGF and MIF mRNA levels were higher in HCC compared to levels in the paired noncancer liver tissues. VEGF and MIF mRNA levels were correlated with tumor stage and metastasis. The expression of VEGF was positively related with MIF expression in HCC.
\end{abstract}

Correspondence to: Dr Xiao-Hui Huang or Dr Wen Li, Department of General Surgical Laboratory, The First Affiliated Hospital of Sun Yat-Sen University, Guangzhou 510080, P.R. China

E-mail: hxiaohui2006@126.com

E-mail:wenli28@163.com

*Contributed equally

Key words: vascular endothelial growth factor, hepatocellular carcinoma, invasion, macrophage migration inhibitory factor
The expression of MIF and VEGF in HCC was markedly positively correlated, which suggests that MIF and VEGF play an important role in the progression of HCC. Both factors may concomitantly accelerate the progression of HCC.

\section{Introduction}

Hepatocellular carcinoma (HCC) is the second most common cause of cancer-related death worldwide and nearly half of all HCC cases occur in China (1). Despite improvements in surgical techniques and the development of novel therapies during the past few decades, the clinical prognosis of HCC patients is still poor due to recurrence and metastasis. The molecular mechanisms involved in HCC development remain obscure. Therefore, it is of great clinical value to further identify malignant factors in order to understand the molecular mechanisms underlying the progression of HCC.

Tumor angiogenesis plays an important role in tumor growth and metastasis (2). Vascular endothelial growth factor (VEGF) has been implicated as an invasion and tumor progression promoter molecule (3). VEGF is a potent mitogen that contributes to both physiological and pathological angiogenesis (4). VEGF is believed to secrete homodimeric glycoprotein that stimulates proliferation and migration of endothelial cells and enhances vascular permeability (5). An increasing number of studies have demonstrated a strong association between overexpression of VEGF and advanced disease or poor prognosis in various types of cancers (6-8). VEGF was recently found to be upregulated in HCC, and it was also shown to be associated with the carcinogenesis, metastasis, recurrence and prognosis of $\operatorname{HCC}(9,10)$. However, further investigation is needed to confirm the molecular mechanisms underlying the effects of VEGF on the development of HCC.

Several mechanisms have been reported to participate in the regulation of VEGF gene expression. Among these, several cytokines or growth factors play a major role. VEGF mRNA expression is rapidly and reversibly induced by epidermal growth factor (EGF), transforming growth factor- $\beta$ (TGF- $\beta$ ), or keratinocyte growth factor (11). Ren et al (12) reported that macrophage migration inhibitory factor (MIF) can stimulate 
the secretion of VEGF from tumor cells. The cytokine MIF is regarded as a major regulator of inflammation and a key mediator that operates as a cytokine and an enzyme (13). Many studies have confirmed the use of MIF as a biomarker for different diseases that have an inflammatory component (14). Moreover, recent studies have demonstrated a role of MIF in tumor growth, such as control of cell proliferation and promotion of angiogenesis (15). MIF also plays an important role in the invasion and metastasis of prostate cancer, lung adenocarcinoma and neuroblastoma cells $(15,16)$. Ren et al (17) found that MIF mRNA was upregulated in HCC tissues when compared with normal liver tissues, suggesting that MIF acts as a regulator of tumor progression in HCC.

The above studies suggest that both VEGF and MIF may be involved in the tumorigenesis of HCC. An examination of whether the aberrant expression of these two proteins is associated with clinicopathological characteristics of HCC patients is therefore warranted. However, to date there has been no report on the clinical relevance of combined VEGF and MIF expression in HCC tissues. To address this problem, the aim of the present study was to further investigate the potential association of the co-expression of VEGF and MIF in HCC tissues with clinicopathologic findings.

\section{Patients and methods}

Patients and tissue specimens. One hundred and fifty pairs of matched HCC and adjacent non-cancer liver tissues were histopathologically and clinically diagnosed at The First Affiliated Hospital of Sun Yat-Sen University from January 2004 to June 2006. Plasma samples from a peripheral vein were also collected from the $150 \mathrm{HCC}$ patients. Plasma samples were obtained from healthy volunteers who underwent physical examination at the First Affiliated Hospital of Sun Yat-Sen University. The 150 patients included 95 males and 55 females. The mean age of the patients was 58 years (range, 20-78 years). Clinicopathological classification and staging were carried out according to the 6th edition of the American Joint Committee on Cancer (AJCC) TNM classification system. Another independent 48 patients with histologically proven $\mathrm{HCC}$ were included in this study. These 48 pairs of tumor tissues from HCC patients and paired adjacent non-cancer specimens were collected for real-time RT-PCR analysis as previously described (18). The study protocol was approved by the Ethics Committee of the First Affiliated Hospital of Sun Yat-Sen University. Informed consent was obtained from all patients prior to surgery. All patients were recruited into this study after providing informed consent.

Enzyme-linked immunosorbent assay. All peripheral blood samples were acquired following a standard collection protocol. Briefly, samples were collected and anticoagulated by ethylene diamine tetraacetic acid (EDTA) and centrifuged for $10 \mathrm{~min}$ at $3000 \mathrm{rpm}$. The serum fractions were aliquoted and stored at $-80^{\circ} \mathrm{C}$ until analysis. The concentrations of serum MIF were measured by quantitative sandwich enzyme-linked immunosorbent assay (ELISA) kits (Quantikine, R\&D Systems, Minneapolis, MN, USA) according to the manufacturer's protocols. The levels of serum VEGF were determined using ELISA kits (Genzyme Corp., USA).
Tissue microarray construction. The representative areas of each HCC specimen or paired adjacent non-cancer liver tissue were punched with a tissue cylinder ( $1 \mathrm{~mm}$ in diameter) from formalin-fixed/paraffin-embedded tumor tissues or paired adjacent non-cancer tissue blocks. The selected tissue cores were precisely arrayed into a new recipient microarray block using a tissue arrayer (Beecher Instrument, Silver Spring, MD, USA). Each sample was arrayed in triplicate.

Immunohistochemistry. Immunohistochemical analysis was performed to study MIF and VEGF expression in 150 human HCC tissues and paired adjacent non-cancer tissues. Briefly, paraffin-embedded tissue-microarray blocks of HCC tissues and paired adjacent non-cancer tissues were consecutively cut into $4-\mu \mathrm{m}$ sections. Slides were baked at $60^{\circ} \mathrm{C}$ for $1-2 \mathrm{~h}$ and then deparaffinized and rehydrated. Endogenous peroxidase activity was blocked by incubation with 3\% hydrogen peroxide for $20 \mathrm{~min}$ at room temperature. Slides were incubated overnight at $4^{\circ} \mathrm{C}$ with primary antibodies (Abcam, Cambridge, UK; catalog no. ad55445; 1:500 dilution) and VEGF (Santa Cruz Biotechnology, Santa Cruz, CA, USA; 1:200 dilution) diluted in phosphate-buffered saline (PBS). After washing, the tissue slides were subsequently treated with the secondary antibody (anti-Rb or mouse IgG/HRP; Zhongshan, 1:2000) for $1 \mathrm{~h}$ at room temperature, and then with 3,3'-diaminobenzidine (DAB) solution followed by counterstaining with hematoxylin . Analysis was performed with a Zeiss Axioscope 2 microscope at a $\times 400$ magnification, respectively. The degree of immunohistochemical staining was semi-quantitatively assessed and scored independently by two observers. For levels of MIF and VEGF expression, staining intensity was scored according to the following criteria: no staining, 0 ; weak staining, 1 ; moderate staining, 2; and strong staining, 3 .

RNA extraction and real-time polymerase chain reaction $(P C R)$. Total RNA was extracted from the tissue samples using Trizol (Invitrogen) according to the manufacturer's instructions. Real-time PCR amplifications were performed in ABI PRISM 7900 Sequence Detection System (Applied Biosystems, Foster City, CA, USA) using EvaGreen ${ }^{\mathrm{TM}}$ qPCR Master Mix (Biotium, Hayward, CA, USA). The primers for human VEGF were 5'-TCGAGACCCTGGTGGACATC-3' (forward) and 5'-TGTTGGACTCCTCAGTGGGC-3' (reverse). MIF primers were 5'-CAGAACCGCTCCTACAGCAAG-3' (forward) and 5'-CGGCTCTTAGGCGAAGGTG-3' (reverse) and $\beta$-actin primers were 5'-ACAATGTGGCCGAGGACTTT-3' (forward) and 5'-GGAGAGGACTGGGCCATTCT-3' (reverse). The optimal PCR amplification for VEGF and MIF was $95^{\circ} \mathrm{C}$ for $30 \mathrm{sec}$ followed by 40 cycles $\left(95^{\circ} \mathrm{C}\right.$ for $5 \mathrm{sec}, 60^{\circ} \mathrm{C}$ for $\left.30 \mathrm{sec}\right)$. The expression of $\beta$-actin was used as the internal control. The relative expression levels of VEGF and MIF mRNA were calculated according to the comparative $\mathrm{Ct}$ method, and the expression of target genes was normalized to $\beta$-actin expression levels in each sample.

Statistical analysis. Data are presented as means \pm standard deviation (SD). All statistical analyses were performed using SPSS 13.0 for Windows (SPSS Inc., Chicago, IL, USA). $\chi^{2}$ test or Fisher's exact test was used for comparisons between immunohistochemical and serum results and clinicopathological 


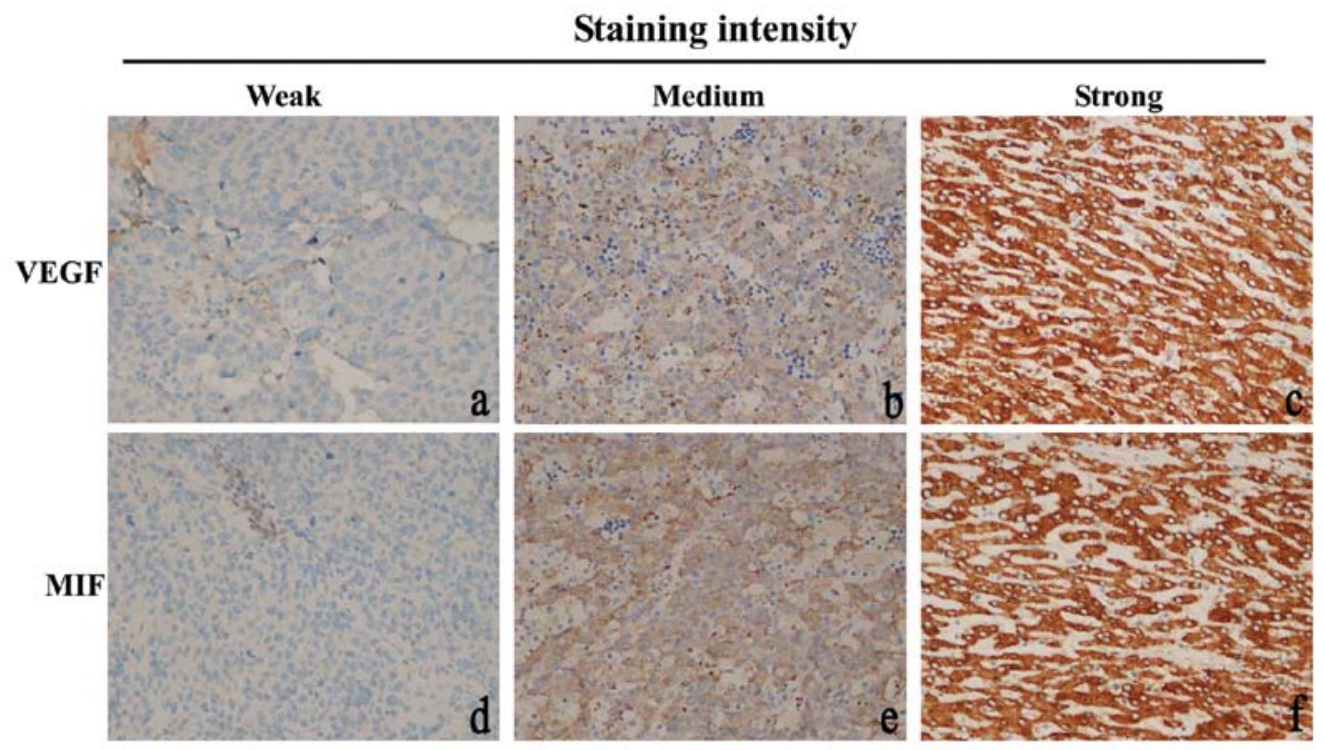

Figure 1. Immunohistochemical staining of VEGF and MIF in human hepatocellular carcinoma (HCC) tissues (magnification, x200). The positive staining of $\operatorname{VEGF}$ (a, weak staining intensity; b, medium staining intensity; c, strong staining intensity) and MIF (d, weak intensity; e, medium intensity; f, strong intensity) was localized in the cytoplasm of HCC cells. Results are representatives of the immunostainings of the specimens.

Table I. Comparison of serum VEGF and MIF levels between HCC patients and the control group.

\begin{tabular}{lrcr}
\hline & $\mathrm{n}$ & Means \pm SD & P-value \\
\hline VEGF & & & 0.011 \\
Patients with HCC & 150 & $414.71 \pm 41.92(\mathrm{ng} / \mathrm{l})$ & \\
Control & 30 & $176.52 \pm 32.14(\mathrm{ng} / \mathrm{l})$ & \\
MIF & & & 0.032 \\
Patients with HCC & 150 & $123.71 \pm 18.34(\mu \mathrm{g} / \mathrm{l})$ & \\
Control & 30 & $11.53 \pm 5.47(\mu \mathrm{g} / \mathrm{l})$ & \\
\hline
\end{tabular}

parameters. Spearman's bivariate correlation test was used to evaluate the correlation between VEGF and MIF. Differences in VEGF mRNA and MIF mRNA expression between the groups were analyzed by the Student's t-test. A P-value $<0.05$ was considered to indicate a statistically significant result.

\section{Results}

Upregulation of VEGF and MIF in serum samples of patients with HCC. Using ELISA, the levels of serum VEGF and MIF were evaluated in 150 patients with HCC and 30 normal volunteers. The serum VEGF and MIF levels were significantly higher in patients with HCC when compared with their levels in the normal controls (Table I). Overexpression of serum VEGF and MIF was significantly associated with tumor size, intrahepatic metastasis, vascular invasion and TNM stage (Table II). Furthermore, the high levels of VEGF in the serum were positively related with serum MIF expression in HCC $(r=0.579, \mathrm{P}<0.05)$.

Overexpression of VEGF and MIF in archived HCC tissues. In subsequent studies, we detected the role of VEGF and
MIF in the clinical progression of HCC. We examined 150 paraffin-embedded, archived HCC tissues, including 30 cases of stage I, 80 cases of stage II and 40 cases of stage III tumors, using immunohistochemical staining. High levels of VEGF were present in the cytoplasm of the malignant cells in $75 \%$ (112/150) of HCC tissues (Fig. lb and c). In contrast, VEGF was negatively or only weakly detectable in adjacent non-cancer tissues (Fig. 1a). In addition, the index values of VEGF staining were significantly increased with the progression of tumor grades I to III $(\mathrm{P}=0.028)$. Moreover, VEGF expression was strongly correlated with tumor size $(\mathrm{P}=0.027)$, vascular invasion $(\mathrm{P}=0.032)$, and serum AFP levels $(\mathrm{P}=0.043)$. However, our analyses did not show significant associations between VEGF expression and other clinical features including age, gender, history of hepatitis, liver cirrhosis and tumor multiplicity (Table III).

MIF was localized in the cytoplasm of positive staining HCC cells (Fig. 1d-f). MIF was detected in 81\% (121/150) of HCC cases $(\mathrm{P}<0.001)$. Our studies showed that high levels of MIF expression were associated with tumor size $(\mathrm{P}=0.022)$, tumor grade $(\mathrm{P}=0.013)$, presence of intrahepatic metastasis $(\mathrm{P}=0.039)$ and vascular invasion $(\mathrm{P}=0.027)$ and TNM stage $(\mathrm{P}=0.013)$. There were no further associations with other clinicopathological parameters (Table III). Spearman correlation analysis confirmed that VEGF expression was positively correlated with MIF protein expression $(\mathrm{r}=0.619, \mathrm{P}=0.022)$ in the $\mathrm{HCC}$ tissues.

VEGF and MIF mRNA expression in HCC and correlations between VEGF and MIF mRNA expression. To confirm the effect of VEGF and MIF on the progression of HCC and their correlation, we examined their mRNA levels in 48 HCCs and paired adjacent non-tumor tissues by real-time RT-PCR. The mRNA level of VEGF was significantly increased in the HCC tissues when compared with the level in the paired adjacent non-tumor tissues $(\mathrm{P}<0.01)$ (Fig. 2A). In HCC tissues, VEGF mRNA expression increased according to increasing TNM stage (Fig. 2C). The mRNA level of VEGF was significantly 
Table II. Correlation between serum VEGF and MIF levels and the clinicopathological characteristics of the HCC patients.

\begin{tabular}{|c|c|c|c|c|c|}
\hline Variable feature & $\mathrm{n}$ & VEGF (ng/l) & P-value & $\operatorname{MIF}(\mu \mathrm{g} / \mathrm{l})$ & P-value \\
\hline Tumor size (cm) & & & 0.011 & & 0.027 \\
\hline$\leq 5$ & 46 & $295.9 \pm 26.9$ & & $58.7 \pm 13.8$ & \\
\hline$>5$ & 104 & $368.7 \pm 34.8$ & & $116.8 \pm 23.8$ & \\
\hline TNM stage & & & 0.032 & & 0.034 \\
\hline I & 30 & $306.7 \pm 42.9$ & & $65.3 \pm 16.9$ & \\
\hline II & 80 & $412.5 \pm 51.3$ & & $118.7 \pm 24.2$ & \\
\hline III & 40 & $634.6 \pm 73.4$ & & $143.5 \pm 26.3$ & \\
\hline Vascular invasion & & & 0.028 & & 0.035 \\
\hline Absence & 103 & $312.3 \pm 40.4$ & & $85.9 \pm 14.7$ & \\
\hline Presence & 47 & $586.7 \pm 64.8$ & & $118.7 \pm 21.3$ & \\
\hline Intrahepatic metastasis & & & 0.031 & & 0.026 \\
\hline Absence & 93 & $337.4 \pm 36.5$ & & $91.8 \pm 25.9$ & \\
\hline Presence & 57 & $668.3 \pm 54.6$ & & $129.7 \pm 34.6$ & \\
\hline
\end{tabular}
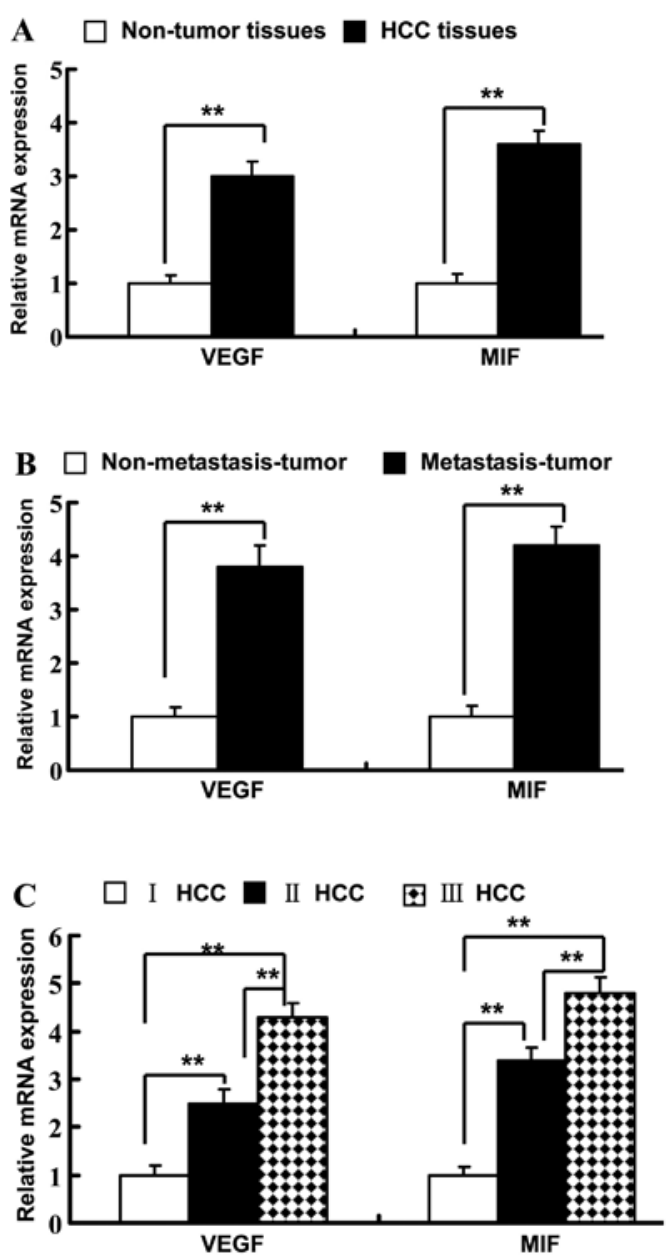

Figure 2. Quantitative PCR analysis of VEGF and MIF mRNA expression in (A) hepatocellular carcinoma (HCC) and paired adjacent non-cancer liver tissues, (B) nonmetastatic and metastatic $\mathrm{HCC}$ and (C) HCC with varied TNM stages. ${ }^{* *} \mathrm{P}<0.01$.

increased in metastatic HCC tissues when compared with the level in the nonmetastatic tissues (Fig. 2B). Consistent with
VEGF, the MIF mRNA level was markedly higher in the HCC tissues when compared with the level in the adjacent non-tumor tissues $(\mathrm{P}<0.001)$ (Fig. 2A). MIF mRNA expression was significantly elevated in later TNM stages $(\mathrm{P}<0.001)$ (Fig. 2C). MIF mRNA was higher in the metastatic HCC tissues when compared with that in the nonmetastatic tissues (Fig. 2B). A positively correlation was noted between VEGF and MIF mRNA expression $(\mathrm{r}=0.72, \mathrm{P}=0.066)$.

\section{Discussion}

In the present study, we analyzed the expression of VEGF and MIF in HCC and evaluated the levels of VEGF and MIF with the clinicopathological parameters in 150 cases. We measured the concentration of VEGF and MIF in a series of 150 serum samples from HCC patients. Additionally, a series of 30 serum samples from healthy volunteers was selected as controls. Moreover, we assessed the relationship between the levels of VEGF and MIF and the clinicopathological factors of the HCC cases. In the present study, we found that the serum levels of VEGF and MIF were markedly increased in the HCC group when compared to levels in the control group. Overexpression of serum VEGF and MIF was significantly associated with tumor size, tumor grade, intrahepatic metastasis, vascular invasion and TNM stage. Furthermore, high levels of VEGF in the serum were positively co-related with serum MIF expression in HCC. These results were consistent with the expression of VEGF and MIF in HCC tissue samples.

VEGF is known as one of the most potent pro-angiogenic factors (19). Several studies (20-23) have demonstrated that VEGF promotes the growth of local foci of malignant tumors and facilitates metastasis and invasion. VEGF, upregulated in various solid tumors, is closely correlated with pathological characteristics, metastasis and prognosis of tumors. Silencing of MMP-9 and VEGF decreases the recurrence and metastasis of HCC after TACE $(24,25)$. Therefore, VEGF plays an important role in the tumorigenesis of tumors. Our results showed that enhanced VEGF was associated with 
Table III. Correlation between VEGF and MIF expression and the clinicopathological characteristics of the HCC patients.

\begin{tabular}{|c|c|c|c|c|c|c|c|c|c|c|c|}
\hline \multirow[b]{2}{*}{ Variable feature } & \multirow[b]{2}{*}{$\mathrm{n}$} & \multicolumn{4}{|c|}{ VEGF } & \multirow[b]{2}{*}{ P-value } & \multicolumn{4}{|c|}{ MIF } & \multirow[b]{2}{*}{ P-value } \\
\hline & & 0 & 1 & 2 & 3 & & 0 & 1 & 2 & 3 & \\
\hline Age (years) & & & & & & 0.834 & & & & & 0.675 \\
\hline$\geq 50$ & 95 & 22 & 17 & 22 & 34 & & 22 & 16 & 33 & 24 & \\
\hline$<50$ & 55 & 16 & 8 & 12 & 19 & & 7 & 11 & 20 & 17 & \\
\hline Gender & & & & & & 0.712 & & & & & 0.738 \\
\hline Male & 125 & 35 & 24 & 32 & 34 & & 22 & 23 & 43 & 37 & \\
\hline Female & 25 & 3 & 5 & 8 & 9 & & 7 & 3 & 6 & 9 & \\
\hline Etiology & & & & & & 0.411 & & & & & 0.513 \\
\hline Noninfection & 29 & 8 & 7 & 10 & 4 & & 12 & 3 & 8 & 6 & \\
\hline Hepatitis B & 109 & 28 & 20 & 28 & 33 & & 15 & 23 & 36 & 35 & \\
\hline Hepatitis C or other & 12 & 2 & 2 & 3 & 5 & & 2 & 1 & 5 & 4 & \\
\hline Liver cirrhosis & & & & & & 0.038 & & & & & 0.041 \\
\hline Absence & 44 & 15 & 11 & 10 & 8 & & 11 & 7 & 14 & 12 & \\
\hline Presence & 106 & 23 & 14 & 30 & 39 & & 18 & 22 & 42 & 24 & \\
\hline Tumor size (cm) & & & & & & 0.027 & & & & & 0.022 \\
\hline$\leq 5$ & 46 & 10 & 8 & 18 & 10 & & 11 & 7 & 17 & 11 & \\
\hline$>5$ & 104 & 28 & 21 & 23 & 32 & & 18 & 21 & 36 & 29 & \\
\hline Serum AFP $(\mu \mathrm{g} / 1)$ & & & & & & 0.043 & & & & & 0.037 \\
\hline$\leq 20$ & 42 & 14 & 7 & 10 & 11 & & 6 & 12 & 14 & 10 & \\
\hline$>20$ & 108 & 24 & 23 & 31 & 30 & & 23 & 15 & 39 & 31 & \\
\hline TNM stage & & & & & & 0.0283 & & & & & 0.0134 \\
\hline I & 30 & 19 & 3 & 5 & 4 & & 10 & 6 & 8 & 6 & \\
\hline II & 80 & 9 & 14 & 26 & 31 & & 11 & 10 & 35 & 24 & \\
\hline III & 40 & 10 & 8 & 12 & 10 & & 8 & 7 & 14 & 11 & \\
\hline Vascular invasion & & & & & & 0.0315 & & & & & 0.0267 \\
\hline Absence & 103 & 31 & 20 & 23 & 29 & & 20 & 21 & 37 & 25 & \\
\hline Presence & 47 & 7 & 8 & 19 & 13 & & 9 & 6 & 15 & 17 & \\
\hline Intrahepatic metastasis & & & & & & 0.0437 & & & & & 0.0391 \\
\hline Absence & 93 & 30 & 18 & 23 & 22 & & 19 & 17 & 31 & 26 & \\
\hline Presence & 57 & 8 & 10 & 18 & 21 & & 10 & 10 & 22 & 15 & \\
\hline
\end{tabular}

intrahepatic metastasis, vascular invasion and later tumor stage. In addition, VEGF expression was positively correlated with MIF expression in the serum of patients with HCC. Furthermore, quantitative PCR verified that VEGF mRNA was significantly upregulated in HCC tissues when compared with that in adjacent non-tumor tissues; there was a correlation between the upregulation of VEGF mRNA with tumor TNM stage and metastasis in HCC.

MIF was initially found to contribute to the inhibition of the random migration of macrophages (26). Recent studies have extablished that MIF plays an important role in carcinogenesis by promoting cell proliferation, tumor angiogenesis and metastasis (27). He et al (28) demonstrated that epithelial and serum MIF expression was progressively increased in gastric cancer. Bando et al (29) found that MIF was overexpressed in 93 breast cancer tissues as detected by ELISA. In esophageal squamous cell carcinoma, MIF expression was found to be correlated with lymph node status (12). In the present study, the immuno- histochemical and ELISA results showed that MIF expression was correlated with increasing tumor grade, intrahepatic metastasis and vascular invasion. Moreover, MIF expression was positively correlated with VEGF expression. Thus, these results suggest that activated MIF/VEGF is involved in proliferation, invasion and metastasis in HCC. Choudhary et al (30) reported that treatment with inhibitors of MIF increased mRNA expression and protein secretion of VEGF in bladder cancer. Bondza et al (31) indicated that MIF markedly stimulates the secretion of VEGF, which is in accordance with the findings of the present study.

MIF and VEGF were overexpressed in patients with HCC in our study and their expression was correlated with tumor size, intrahepatic metastasis and vascular invasion. MIF stimulation may induce an increase in VEGF secretion, which contributes to angiogenesis and tumor growth. Therefore, VEGF and MIF may be markers of more aggressive HCC and they could be therapeutic targets for patients with HCC. 


\section{Acknowledgements}

This study was supported by the National Natural Science Foundation of China (81071871, 81108162, 81172079), the Natural Science Foundation of Guangdong Province, China (S2013010016831), the Science and Technology Planning Project of Guangdong Province, China (2010b060500007; 2011B060300012), and the Foundation for Youth Teachers by Sun Yat-Sen University (11ykpy16).

\section{References}

1. Jemal A, Bray F, Center MM, Ferlay J, Ward E and Forman D: Global cancer statistics. CA Cancer J Clin 61: 69-90, 2011.

2. Hanahan D and Folkman J: Patterns and emerging mechanisms of the angiogenic switch during tumorigenesis. Cell 86: 353-364, 1996.

3. Amini A, Masoumi Moghaddam S, Morris DL and Pourgholami MH: The critical role of vascular endothelial growth factor in tumor angiogenesis. Curr Cancer Drug Targets 12: 23-43, 2012.

4. Arcondéguy T, Lacazette E, Millevoi S, Prats H and Touriol C: VEGF-A mRNA processing, stability and translation: a paradigm for intricate regulation of gene expression at the posttranscriptional level. Nucleic Acids Res 41: 7997-8010, 2013.

5. Ferrara $\mathrm{N}$ and Davis-Smyth T: The biology of vascular endothelial growth factor. Endocr Rev 18: 4-25, 1997.

6. Koukourakis MI, Papazoglou D, Giatromanolaki A, Bougioukas G, Maltezos E and Sivridis E: VEGF gene sequence variation defines VEGF gene expression status and angiogenic activity in non-small cell lung cancer. Lung Cancer 46: 293-298, 2004.

7. Jin Q, Hemminki K, Enquist K, Lenner P, Grzybowska E, Klaes R, Henriksson R, Chen B, Pamula J, Pekala W, Zientek H, Rogozinska-Szczepka J, Utracka-Hutka B, Hallmans G and Försti A: Vascular endothelial growth factor polymorphisms in relation to breast cancer development and prognosis. Clin Cancer Res 11: 3647-3653, 2005.

8. Celen O, Kahraman I, Yildirim E and Berberoglu U: Correlation of vascular endothelial growth factor (VEGF) and CEA with clinicopathological variables in colorectal cancer patients. Neoplasma 51: 293-299, 2004.

9. Shen YC, Hsu C and Cheng AL: Molecular targeted therapy for advanced hepatocellular carcinoma: current status and future perspectives. J Gastroenterol 45: 794-807, 2010.

10. Chen L, Shi Y, Jiang CY, Wei LX, Lv YL, Wang YL and Dai GH: Coexpression of PDGFR-alpha, PDGFR-beta and VEGF as a prognostic factor in patients with hepatocellular carcinoma. Int J Biol Markers 26: 108-116, 2011.

11. Ferrara N, Gerber HP and LeCouter J: The biology of VEGF and its receptors. Nat Med 9: 669-676, 2003.

12. Ren Y, Law S, Huang X, Lee PY, Bacher M, Srivastava G and Wong J: Macrophage migration inhibitory factor stimulates angiogenic factor expression and correlates with differentiation and lymph node status in patients with esophageal squamous cell carcinoma. Ann Surg 242: 55-63, 2005.

13. Greven D, Leng L and Bucala R: Autoimmune diseases: MIF as a therapeutic target. Expert Opin Ther Targets 14: 253-264, 2010.

14. Grieb G, Merk M, Bernhagen J and Bucala R: Macrophage migration inhibitory factor (MIF): a promising biomarker. Drug News Perspect 23: 257-264, 2010.

15. Meyer-Siegler KL, Iczkowski KA, Leng L, Bucala R and Vera PL: Inhibition of macrophage migration inhibitory factor or its receptor (CD74) attenuates growth and invasion of DU-145 prostate cancer cells. J Immunol 177: 8730-8739, 2006.

16. Ren Y, Chan HM, Fan J, Xie Y, Chen YX, Li W, Jiang GP, Liu Q, Meinhardt A and Tam PK: Inhibition of tumor growth and metastasis in vitro and in vivo by targeting macrophage migration inhibitory factor in human neuroblastoma. Oncogene 25: $3501-3508,2006$.
17. Ren Y, Tsui HT, Poon RT, Ng IO, Li Z, Chen Y, Jiang G, Lau C, Yu WC, Bacher M and Fan ST: Macrophage migration inhibitory factor: roles in regulating tumor cell migration and expression of angiogenic factors in hepatocellular carcinoma. Int J Cancer 107: 22-29, 2003.

18. Yang XW, Zhang LJ, Huang XH, Chen LZ, Su Q, Zeng WT, Li W and Wang Q: miR-145 suppresses cell invasion in hepatocellular carcinoma cells: miR-145 targets ADAM17. Hepatol Res: Apr 28, 2013 (Epub ahead of print). doi: 10.1111/hepr.12152.

19. Namisaki T, Yoshiji H, Noguchi R, Ikenaka Y, Kitade M, Kaji K, Shirai Y, Aihara Y, Yoshii J, Yanase K, Tsujimoto T, Kawaratani H and Fukui $H$ : The vascular endothelial growth factor (VEGF) receptor-2 is a major regulator of VEGF-mediated salvage effect in murine acute hepatic failure. J Angiogenes Res 2: 16, 2010.

20. Hu J, Chen C, Su Y, Du J, Qian X and Jin Y: Vascular endothelial growth factor promotes the expression of cyclooxygenase 2 and matrix metalloproteinases in Lewis lung carcinoma cells. Exp Ther Med 4: 1045-1050, 2012.

21. Li C, Liu B, Dai Z and Tao Y: Knockdown of VEGF receptor-1 (VEGFR-1) impairs macrophage infiltration, angiogenesis and growth of clear cell renal cell carcinoma (CRCC). Cancer Biol Ther 12: 872-880, 2011.

22. Yu W, Chen L, Yang YQ, Falck JR, Guo AM, Li Y and Yang J: Cytochrome P450 w-hydroxylase promotes angiogenesis and metastasis by upregulation of VEGF and MMP-9 in non-small cell lung cancer. Cancer Chemother Pharmacol 68: 619-629, 2011.

23. Amano H, Ito $\mathrm{Y}$, Suzuki T, Kato S, Matsui Y, Ogawa F, Murata T, Sugimoto Y, Senior R, Kitasato H, Hayashi I, Satoh Y, Narumiya $S$ and Majima M: Roles of a prostaglandin E-type receptor, EP3, in upregulation of matrix metalloproteinase- 9 and vascular endothelial growth factor during enhancement of tumor metastasis. Cancer Sci 100: 2318-2324, 2009.

24. Deng G, Zhao DL, Li GC, Yu H and Teng GJ: Combination therapy of transcatheter arterial chemoembolization and arterial administration of antiangiogenesis on VX2 liver tumor. Cardiovasc Intervent Radiol 34: 824-832, 2011.

25. Janani P, Sivakumari K, Geetha A, Yuvaraj S and Parthasarathy C: Bacoside A downregulates matrix metalloproteinases 2 and 9 in DEN-induced hepatocellular carcinoma. Cell Biochem Funct 28: 164-169, 2010.

26. David JR: Delayed hypersensitivity in vitro: its mediation by cell-free substances formed by lymphoid cell-antigen interaction. Proc Natl Acad Sci USA 56: 72-77, 1966.

27. Chesney J, Metz C, Bacher M, Peng T, Meinhardt A and Bucala R: An essential role for macrophage migration inhibitory factor (MIF) in angiogenesis and the growth of a murine lymphoma. Mol Med 5: 181-191, 1999.

28. He XX, Yang J, Ding YW, Liu W, Shen QY and Xia HH: Increased epithelial and serum expression of macrophage migration inhibitory factor (MIF) in gastric cancer: potential role of MIF in gastric carcinogenesis. Gut 55: 797-802, 2006.

29. Bando H, Matsumoto G, Bando M, Muta M, Ogawa T, Funata N, Nishihira J, Koike M and Toi M: Expression of macrophage migration inhibitory factor in human breast cancer: association with nodal spread. Jpn J Cancer Res 93: 389-396, 2002.

30. Choudhary S, Hegde P, Pruitt JR, Sielecki TM, Choudhary D, Scarpato K, Degraff DJ and Pilbeam CC: Macrophage migratory inhibitory factor promotes bladder cancer progression via increasing proliferation and angiogenesis. Carcinogenesis: Aug 2, 2013 (Epub ahead of print).

31. Bondza PK, Metz CN and Akoum A: Macrophage migration inhibitory factor up-regulates alpha(v)beta(3) integrin and vascular endothelial growth factor expression in endometrial adenocarcinoma cell line Ishikawa. J Reprod Immunol 77: 142-151, 2008. 